\title{
Impact of discounts on medicine prices
}

\author{
Peter Schneider ${ }^{*}$, Sabine Vogler \\ From 3rd International PPRI Conference 2015: Pharmaceutical Pricing and Reimbursement Policies: Challenges \\ Beyond the Financial Crisis \\ Vienna, Austria. 12-13 October 2015
}

\section{Problem statement}

Several European countries implemented external price referencing (EPR) as a pricing policy for medicines, and as such they use price data from other countries as a benchmark to determine their medicine prices. In current EPR practice undiscounted official list prices are taken as a reference. There is some debate as to which extent discounts have an impact on medicine prices. The aim of the study was to investigate whether and how much medicine prices would change if discounts were considered.

\section{Methodology}

Ex-factory prices of 30 medicines (15 medicines from the out-patient sector and 15 medicines from the in-patient sector) that accounted for high expenditure for public payers in Austria were surveyed for 16 European countries (Belgium, Denmark, Finland, France, Germany, Greece, Hungary, Ireland, Italy, the Netherlands, Portugal, Sweden, Slovakia, Spain and the UK). In addition to these official list prices, the statutorily discounted ex-factory medicines in Germany were collected and compared.

\section{Results}

Overall, for the 30 selected medicines, Germany was the country that had most frequently the highest prices (in $40 \%$ of the 30 medicines), followed by Sweden (23\%) and Denmark (13\%). If discounted medicines instead of list prices were considered for Germany, Sweden was most frequently the highest-priced country (37\% of the medicines), followed by Denmark (17\%). Together with Austria and the UK, Germany ranked third (10\%). In a comparison of list prices only, Swedish prices were in the fourth quartile in $85 \%$ and German prices in $80 \%$ of the medicines. Considering discounted prices for Germany, their prices ranked in the fourth quartile in only $30 \%$ of all medicines, compared with $89 \%$ for Sweden and $47 \%$ for Austria and Denmark respectively. Among the analysed medicines the impact on the price level was strongest for medicines with the comparably highest prices.

\section{Conclusions}

In several European countries pharmaceutical manufacturers grant confidential rebates to public payers [1], leading to lower actual prices compared with list prices. Since EPR is usually based on official list prices, countries risk over-paying. This case study in which statutory, published discounts for a sole country were considered suggests a high impact on medicine prices. Taking discounts into account, medicine price levels in Germany were comparably lower. A consideration of discounts in further countries is likely to show further reductions in medicine price levels. Disclosure of discounts might help improve pricing policies in European countries.

\section{Acknowledgements}

The study was financed by the Austrian Federal Ministry of Health. Price data were provided from the Pharma Price Information (PPI) service of the Austrian Public Health Institute (GÖG).

Published: 5 October 2015

\section{Reference}

1. Vogler S, Zimmermann N, Habl C, Piessnegger J, Bucsics A: Discounts and rebates granted to public payers for medicines in European countries. Southern Med Review 2012, 5(1):38-46.

\section{doi:10.1186/2052-3211-8-S1-O4}

Cite this article as: Schneider and Vogler: Impact of discounts on medicine prices. Journal of Pharmaceutical Policy and Practice 2015 8(Suppl 1): O4.

\footnotetext{
* Correspondence: peter.schneider@goeg.at

WHO Collaborating Centre for Pharmaceutical Pricing and Reimbursement

Policies, Health Economics Department, Gesundheit Österreich GmbH

(Austrian Public Health Institute), Vienna, 1010, Austria
}

C 2015 Schneider and Vogler This is an Open Access article distributed under the terms of the Creative Commons Attribution License (http://creativecommons.org/licenses/by/4.0), which permits unrestricted use, distribution, and reproduction in any medium, provided the original work is properly cited. The Creative Commons Public Domain Dedication waiver (http://creativecommons.org/ publicdomain/zero/1.0/) applies to the data made available in this article, unless otherwise stated. 